\title{
De-novo Gastrointestinal Anastomosis with Lumen Apposing Metal Stent
}

\author{
Deepanshu Jain ${ }^{1}$, Ankit Chhoda ${ }^{2}$, Abhinav Sharma ${ }^{3}$ and Shashideep Singhal ${ }^{4}$ \\ ${ }^{1}$ Division of Gastroenterology and Hepatology, Department of Digestive Diseases and Transplantation, Einstein Healthcare Network, \\ Philadelphia, PA, USA, 'Department of Internal Medicine, Yale-Waterbury Internal Medicine Program, Yale school of medicine, Waterbury, \\ CT, USA, ${ }^{3}$ Department of Internal Medicine, Maulana Azad Medical College, New Delhi, India, ${ }^{4}$ Gastrointestinal Care Consultants PA, \\ Houston, TX, USA
}

Gastric outlet obstruction, afferent or efferent limb obstruction, and biliary obstruction among patients with altered anatomy often require surgical intervention which is associated with significant morbidity and mortality. Endoscopic dilation for benign etiologies requires multiple sessions, whereas self-expandable metal stents used for malignant etiologies often fail due to tumor in-growth. Lumen apposing metal stents, placed endoscopically with the intent of creating a de-novo gastrointestinal anastomosis bypassing the site of obstruction, can potentially achieve similar efficacy, with a much lower complication rate. In our study cohort ( $n=79)$, the composite technical success rate and clinical success rate was $91.1 \%$ (72/79) and 97.2\% (70/72), respectively. Five different techniques were used: $43 \%(34 / 79)$ underwent the balloon-assisted method, 27.9\% (22/79) underwent endoscopic ultrasound-guided balloon occluded gastro-jejunostomy bypass, $20.3 \%$ (16/79) underwent the direct technique, $6.3 \%(5 / 79)$ underwent the hybrid rendezvous technique, and 2.5\% (2/79) underwent natural orifice transluminal endoscopic surgery (NOTES)-assisted procedure. All techniques required an echoendoscope except NOTES. In all, 53.2\% (42/79) had non-cautery enhanced Axios stent, 44.3\% (35/79) had hot Axios stent, and $2.5 \%$ (2/79) had Niti-S spaxus stent. Symptom-recurrence was seen in $2.8 \%$, and $6.3 \%$ had a complication (bleeding, abdominal pain or peritonitis). All procedures were performed by experts at centers of excellence with adequate surgical back up.

Clin Endosc 2018;51:439-449

Key Words: De-novo entero-enteric anastomosis; Lumen apposing metal stents; Endosonography

\section{INTRODUCTION}

Gastric outlet obstruction (GOO), afferent limb syndrome (ALS), or biliary obstruction, in patients with altered gastrointestinal (GI) tract anatomy, are the most common presentations in clinical practice which require either surgical and/or

Received: May 3, 2018 Revised: June 25, 2018

Accepted: July 15, 2018

Correspondence: Deepanshu Jain

Division of Gastroenterology and Hepatology, Department of Digestive Diseases and Transplantation, Einstein Healthcare Network, Einstein Medical Center Philadelphia, 5401 Old York Road Klein 505, Philadelphia, PA 19141, USA

Tel: +1-215-456-8210, Fax: +1-215-456-7926, E-mail: deepanshu.jain.25@gmail. com

ORCID: https://orcid.org/0000-0002-0678-3515

(c) This is an Open Access article distributed under the terms of the Creative Commons Attribution Non-Commercial License (http://creativecommons.org/ licenses/by-nc/3.0) which permits unrestricted non-commercial use, distribution, and reproduction in any medium, provided the original work is properly cited. endoscopic drainage. Traditionally, endoscopic dilation for benign etiologies and surgery for malignant etiologies has been the standard course of treatment. ${ }^{1}$ However, endoscopic dilations require multiple sessions and have variable outcomes, including the risk of perforation. ${ }^{2-4}$ Surgical bypass is limited by significant morbidity, prolonged recovery time, and high operative costs. ${ }^{5.7}$ In cancer patients with poor surgical tolerance, endoscopic placement of self-expanding metallic stents (SEMS) is an alternative, but is limited by stent obstruction due to tumor ingrowth. ${ }^{1,5-7}$ The same may not even be feasible, if the obstruction has led to complete closure of the lumen.

Endoscopic creation of a de-novo anastomosis with the aid of lumen apposing metal stent (LAMS) is an exciting new technique. It is a less invasive alternative to surgery. It can be a therapeutic or palliative intervention depending on the etiology of obstruction. It enables drainage and efficient transit of GI contents (bile, pancreatic enzymes or food contents) by 
by-passing the site of obstruction which may be due to benign or malignant etiology.

The procedure entails endoscopic localization of two adjacent lumens of the GI tract bypassing the site of obstruction, followed by deployment of LAMS for formation of a fistulous tract. LAMS is a novel saddle shaped, $1-\mathrm{cm}$ long stent, 10 or $15 \mathrm{~mm}$ in diameter with a wide flange of 23 and $28 \mathrm{~mm}$ on either end. The unique saddle shape of LAMS gives it anti-migratory property and allows it to hold the two GI lumens together. The application of LAMS in this clinical setting is an extension of its known indications, and experience thereof, is still evolving. ${ }^{8-10}$

In this article we review the available evidence in form of case reports, case series, retrospective and prospective studies, describing the use of LAMS for de-novo GI anastomosis.

\section{MATERIALS AND METHODS}

An extensive English literature search till December 2017 was performed separately by two authors, using PubMed and Google Scholar, to identify peer reviewed original articles using keywords- Lumen apposing metal stent; Gastroenterostomy; Enteroenteric anastomosis. Only human study subject articles in English literature were selected. Additional relevant studies were identified by manually searching the references of pertinent studies.

\section{RESULTS}

A preliminary search yielded 14 original studies which included 2 prospectively designed studies, ${ }^{11,12} 3$ retrospective studies, ${ }^{13-15} 3$ case series, ${ }^{16-18}$ and 6 case reports. ${ }^{19-24}$ On further reading of selected articles, 2 articles were excluded due to duplication of represented population ${ }^{12,15}$ and one article was excluded due to lack of data regarding the type of stent used. ${ }^{18}$ The etiology and location of obstruction, technical procedure details, stent specifics, outcomes, and complications with their management from each study were reviewed and have been summarized in Tables 1, 2, and 3.

\section{DISCUSSION}

\section{Patient characteristics \\ Demographics}

Out of 11 studies, demographic data was reported in 9 studies. ${ }^{11,13,14,16-21,23,24}$ The mean age of the cohort was 62.9 years, with the range varying from as young as 34 years to as old as
90 years. The study cohort comprised of $50.7 \%$ males (38/75) and $49.3 \%$ females $(37 / 75)$.

\section{Anatomy and indication}

Almost half (51.9\%) of the cohort had pre-existing altered GI anatomy. ${ }^{11,16,17,19-23}$

GOO was the most common indication attributed in $84.8 \%(67 / 79)$ of cases. ${ }^{11,13,14,24}$ The second most common indication was ALS, in $11.4 \%$ (9/79) cases. ${ }^{16,17,20,21}$ The two less common indications were to gain endoscopic access to relieve biliary obstruction $(1.3 \%)^{19}$ and efferent limb obstruction $(2.5 \%))^{22,23}$ In $74.7 \%$ cases, the underlying etiology was malignant, ${ }^{11,13,14,16,17,19-21,24}$ whereas in the rest it was benign $(25.3 \%))^{11,13,17,22,23}$

\section{Prior interventions}

No data was reported regarding prior interventions in $38 \%$ (30/79) of the cohort. ${ }^{14}$ Endoscopic ultrasound (EUS)-guided de-novo anastomosis was the preferred as first line treatment in $26.6 \%(21 / 79)$ cases, ${ }^{11,13,16,21-24}$ and as secondary treatment (after failed primary interventions) in $35.4 \%$ (28/79) patients. ${ }^{11,13,17,19,20}$ Prior interventions included endoscopic dilation, ${ }^{11}$ SEMS, ${ }^{11,13}$ percutaneous endoscopic gastrostomy or jejunostomy, ${ }^{11}$ nasal-jejunal tube, ${ }^{11}$ enteroscopy, ${ }^{17,19}$ endoscopy, ${ }^{20}$ EUS-guided biliary drainage, ${ }^{19}$ percutaneous transhepatic biliary drainage. ${ }^{17,19}$

Demographics, details of underlying etiology, indication, anatomy, and prior interventions in patients from each individual study have been summarized in Table 1 .

\section{Procedure characteristics \\ Technique}

Multiple approaches exist to identify the target small bowel loop.

\section{Incomplete occlusion:}

- Balloon or nasobiliary drain assisted: $:^{11,13,14,19,23,24}$ In this approach, the area of stenosis is traversed either by the endoscope itself or with a guidewire under fluoroscopic guidance (Fig. 1). A balloon dilator or nasobiliary drain is then passed over the guidewire and the balloon is filled with contrast (or the nasobiliary drain is used to insufflate the lumen with water), which can then be localized by an echoendoscope in the stomach (Fig. 2).

- Hybrid rendezvous: ${ }^{11}$ In this approach, the area of stenosis is traversed by an ultra-thin scope, followed by water insufflation of the distal lumen, which can then be identified by an echoendoscope in the stomach.

- EUS-guided balloon occluded gastro-jejunostomy 


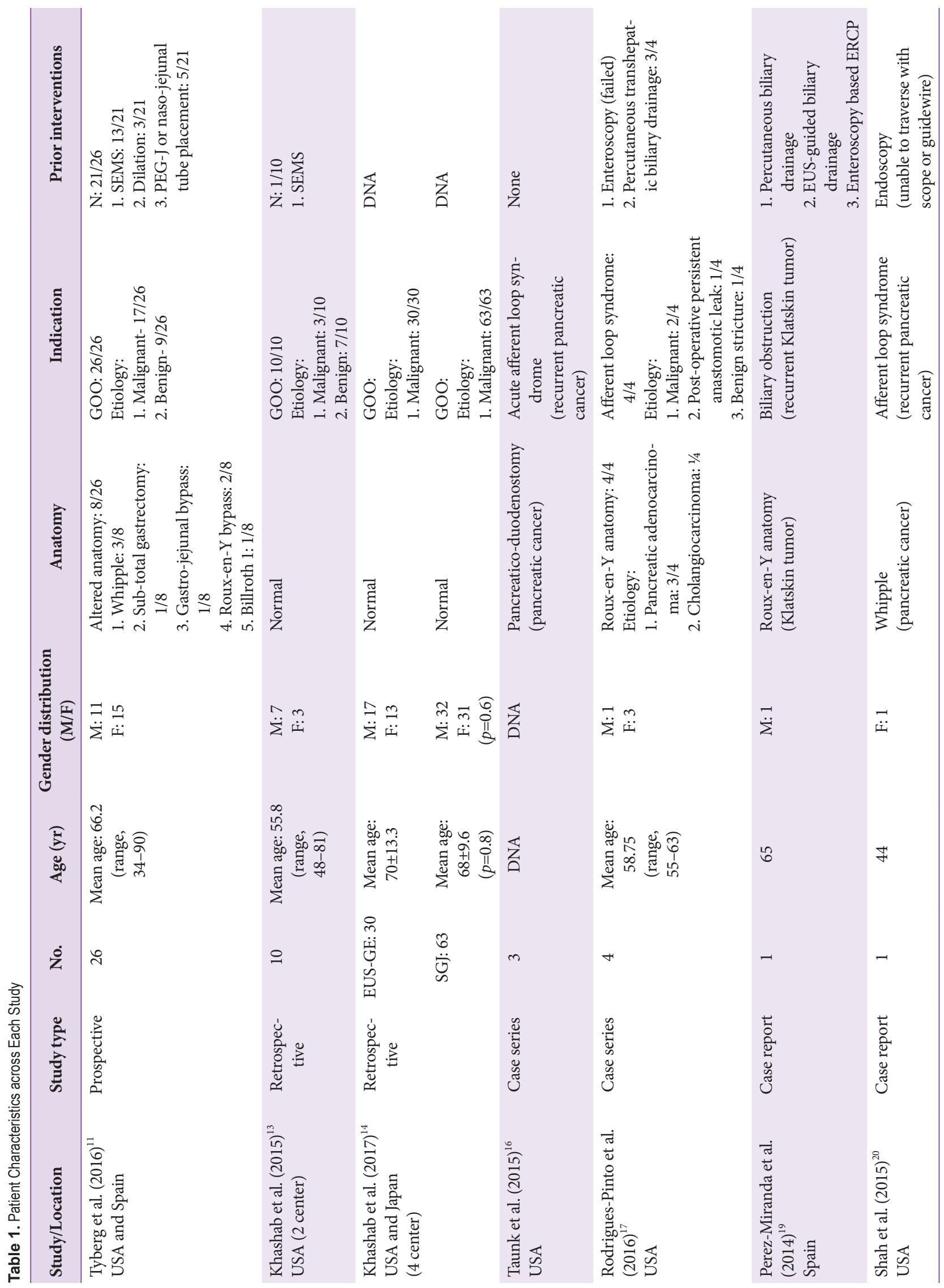




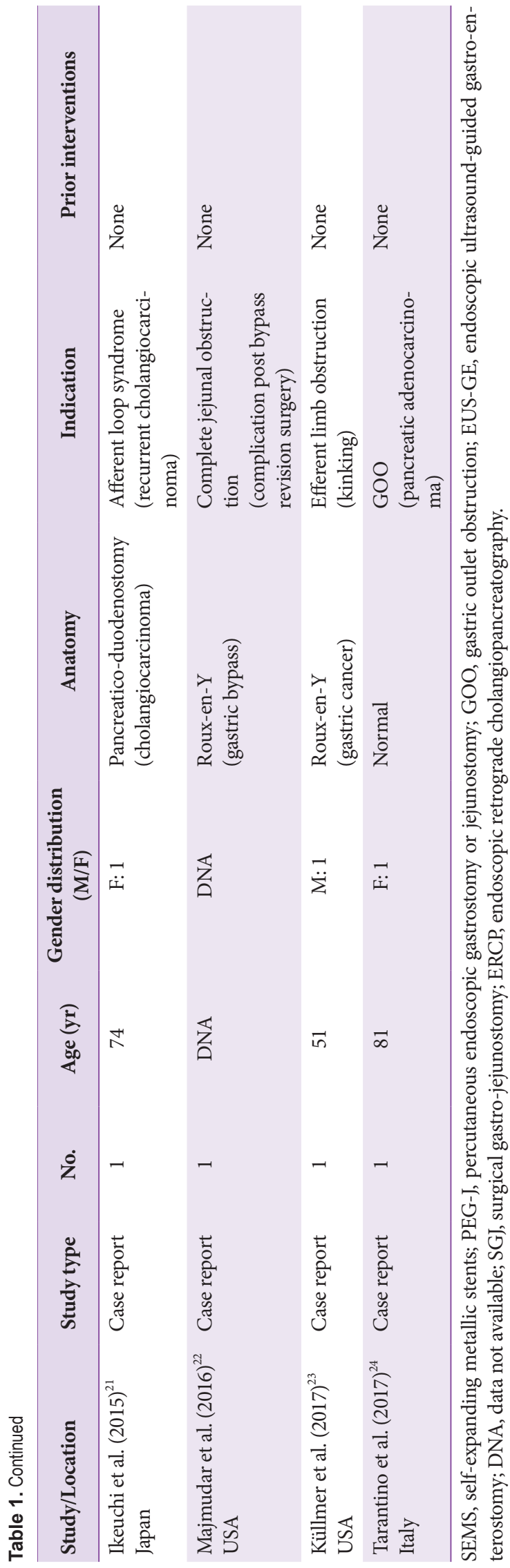

bypass (EPASS): ${ }^{14}$ In this approach, the area of stenosis is first traversed with a guidewire over which a special double balloon enteric tube is passed (Tokyo Medical University Type; Create Medic Co., Yokohama, Japan). The two balloons are then inflated with contrast, followed by saline infusion between the two balloons, which holds the small bowel in close proximity to the gastric lumen and allows easy identification by the echoendoscope.

\section{Complete or incomplete occlusion:}

- Direct technique: $:^{11,13,1,1,16,17,19-24}$ This approach is feasible even in cases where complete lumen obstruction prevents traversing of the site with a scope or a guidewire. The target small bowel loop is identified and confirmed by contrast injection with the help of EUS-guided needle puncture (19 or $22 \mathrm{G}$ ).

- Natural orifice transluminal endoscopic surgery (NOTES): ${ }^{11}$ This approach is feasible even in cases with complete luminal occlusion. Essentially, in this approach, a full thickness gastric wall incision is made followed by dilation to allow the endoscope to enter the peritoneal cavity, where under direct visualization, a small bowel loop is identified, incised, and a guidewire is placed, over which the stent is deployed. This approach does not require an echoendoscope.

In our study cohort, $43 \%$ (34/79) underwent the balloon-assisted method, 27.9\% (22/79) underwent EPASS, 20.3\% (16/79) underwent the direct technique, 6.3\% (5/79) underwent the hybrid rendezvous technique, and 2.5\% (2/79) underwent NOTES assisted de-novo entero-enteric or gastro-enteric anastomosis. ${ }^{11,13,14,16,17,19-24}$ Chen et al. compared the balloon-assisted and direct EUS-guided techniques and found similar clinical and technical success rates (TSRs), but the mean duration of the procedure was significantly lower in the direct technique $(35.1 \pm 31.2 \mathrm{~min})$ in contrast to the balloon-assisted technique $(89.9 \pm 33.3 \mathrm{~min}) .^{15}$

Once the target bowel loop has been identified, the next step depends on whether the intent is to use a cautery enhanced LAMS apparatus or non-cautery enhanced LAMS apparatus. The latter requires puncturing of the target lumen (if containing the contrast filled balloon, will leak into the puncture, thus helping to confirm the lumen location) with an EUS-guided needle (19 or $20 \mathrm{G}$ ). This is followed by passage of a guidewire ( 0.035 inch diameter), balloon dilation of the tract (it is not advisable to dilate more than 4-6 mm, as it may lead to spontaneous misplacement of LAMS), and then deployment of LAMS (distal flange first followed by the proximal flange). Conversely, cautery enhanced LAMS combines 

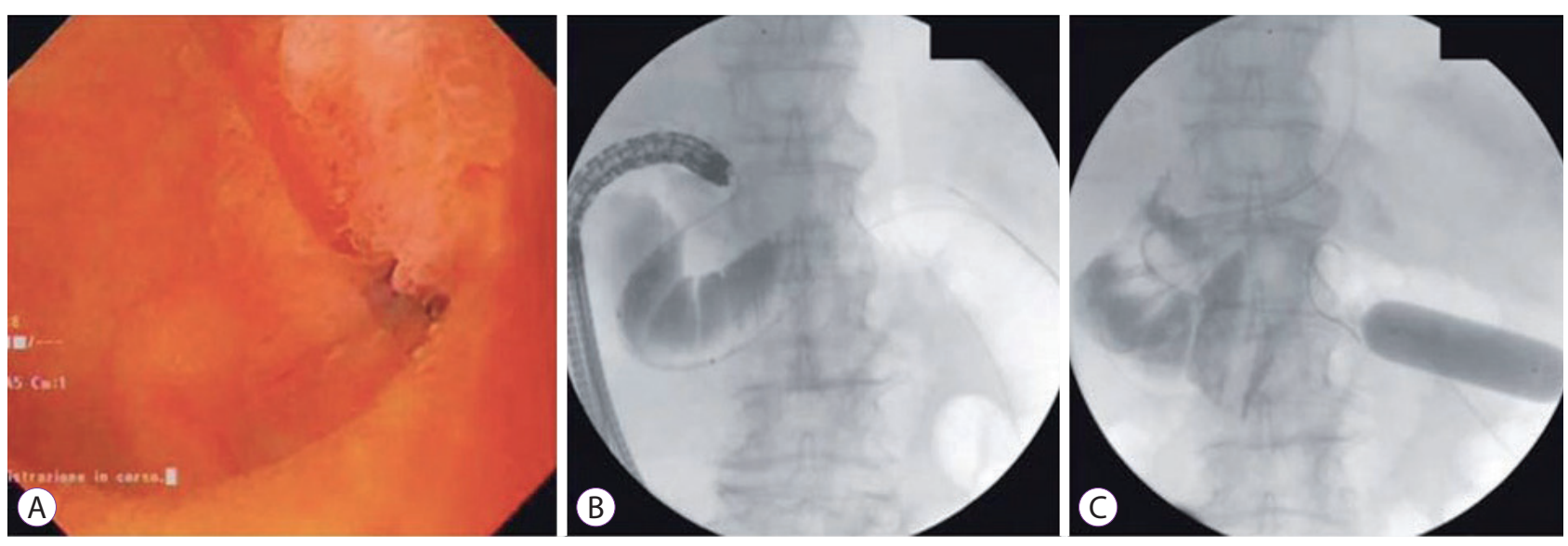

Fig. 1. Introduction of the guidewire. (A) Endoscopic view of the duodenal stenosis. (B) Fluoroscopic view of the guidewire introduced through the stenosis of the small bowel. (C) Fluoroscopic view of a 20-mm balloon dilator inflated with contrast fluid within the small bowel (Re-produced with permission from Thieme publishers).
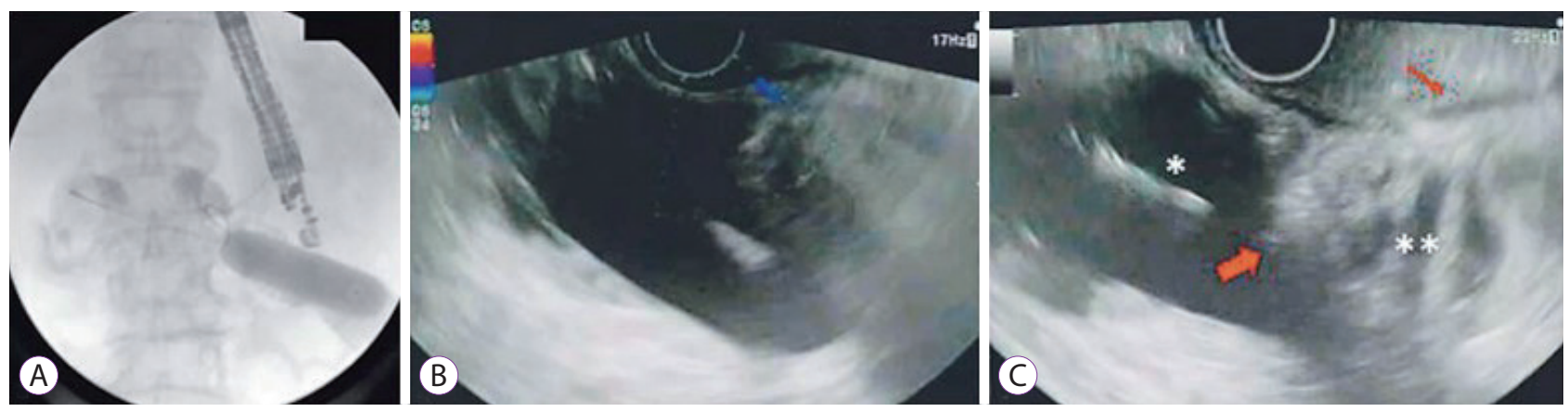

Fig. 2. The balloon dilator inside the small bowel loop. (A) Fluoroscopic view of the echoendoscope in the stomach next to the inflated balloon within the adjacent jejunal loop. (B) Echoendoscopic view showing the inflated balloon. (C) Echoendoscope view showing the inflated balloon (*), the tip of the delivery system of the stent (fat arrow) inside the jejunal lumen $\left({ }^{* *}\right)$, and the gastric wall (thin arrow) (Re-produced with permission from Thieme publishers).
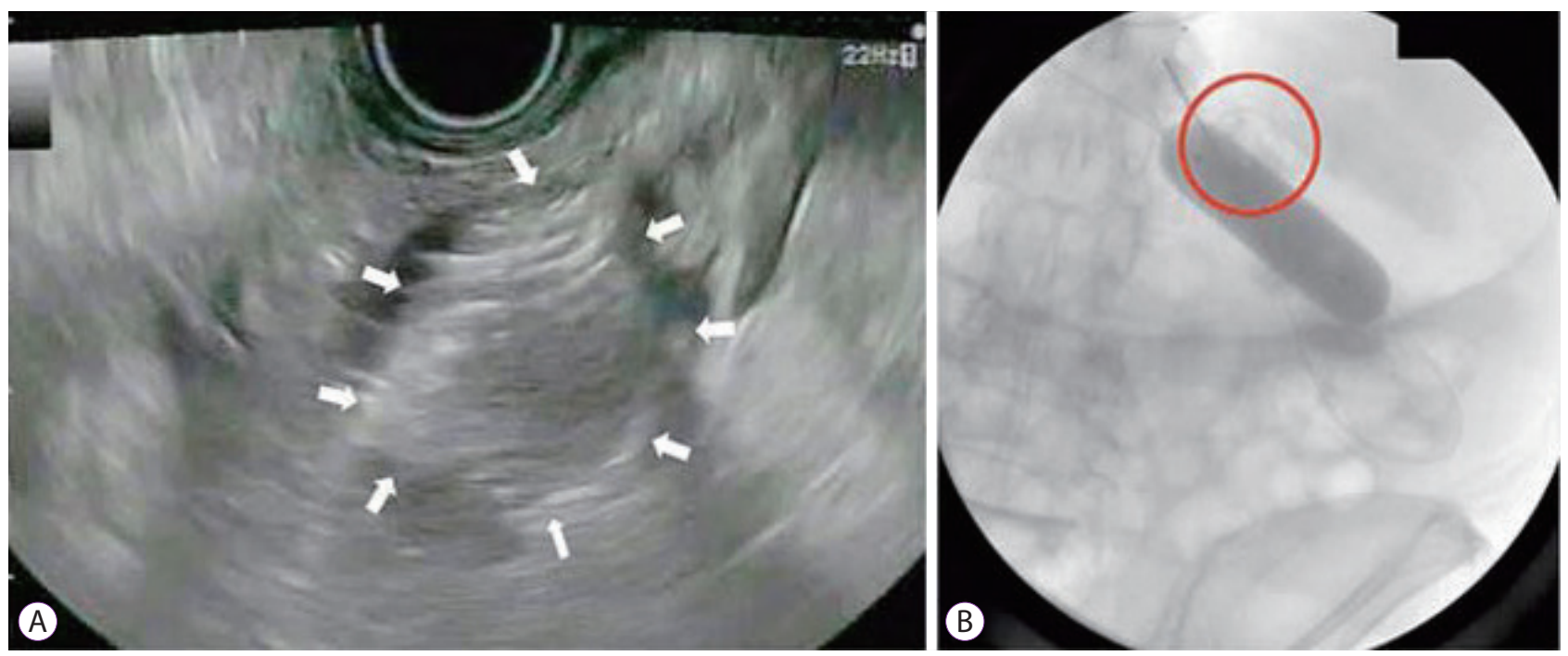

Fig. 3. Deployment of the stent. (A) Echoendoscopic view of the released distal flange of the stent (arrows) into the lumen of the jejunal loop. (B) Fluoroscopic view of the fully released stent (circle) and the intact balloon (Re-produced with permission from Thieme publishers).

all these steps into one step (Fig. 3). LAMS can be deployed under direct EUS guidance alone or in combination with flu- oroscopy. Once the LAMS is deployed, a 10 or $15 \mathrm{~mm}$ balloon dilator is used to dilate the stent to its intended size. In our 
study cohort, two types of LAMS were used- Axios (non-cautery enhanced or hot) ${ }^{11,13,14,16,17,19-24}$ and Niti-S Spaxus. ${ }^{14}$ In all, 53.2\% (42/79) had non-cautery enhanced Axios stent, 44.3\% (35/79) had hot Axios stent, and 2.5\% (2/79) had Niti-S spaxus stent. ${ }^{11,13,14,16,17,19-24}$ The stent size and type for each study has been summarized in the Table 2 .

As the small bowel is mobile, keeping the target loop stationary and in close proximity of the site of intended therapeutic intervention is challenging. To achieve stability, several approaches have been described:

- Glucagon administration to decrease peristaltic movements

- Snare-balloon technique- A snare is attached over the balloon catheter and is used to catch the guidewire passed through the EUS needle. This is followed by application of tension on the snare/balloon apparatus which helps to keep the target bowel loop fixed in place. ${ }^{13}$ A modification of this technique was described by Ngamruengphong et al. where both ends of the guidewire are pulled (externally) to achieve the same outcome. $^{18}$

In addition, few authors chose to place a pigtail catheter through the LAMS to prevent any recurrence of obstruction. ${ }^{17,20}$ This practice has been shown to be useful at alternative sites like choledocho-enterostomy and cholecysto-enterostomy creation with LAMS. ${ }^{8,9}$

\section{Type of anastomosis}

Majority of our cohort, i.e. 93.5\% (73/78) had a gastro-enterostomy, whereas only a small fraction had entero-enterostomy $(5 / 78){ }^{11,13,14,16,17,19-24}$

All procedure and stent specific details for each study have been summarized in Table 2.

\section{Outcomes \\ Follow up}

Each author reported a variety of modalities to follow up their patient's post-procedure: either clinically alone or in combination with radiological studies like- upper GI series, computed tomography scan, or endoscopy. Similarly, a wide variation was noted in the follow up period across the studies as has been summarized in the Table 3 .

\section{Technical success and failure}

Technical success was defined by adequate placement of LAMS. In total, 79 patients from 11 individual studies underwent EUS-guided de-novo entero-enteric anastomosis. Composite TSR for the cohort was 91.1\% (72/79). Individual
TSR was $100 \%$ for eight studies. ${ }^{16,17,19-24}$ For the remaining three, the TSR was $92 \%(24 / 26), 90 \%$ (9/10), and $87 \%(26 / 30)$, respectively. ${ }^{11,13,14}$ Tyberg et al. reported initial misplacement of LAMS in 7 patients $(7 / 26) .{ }^{11}$ The authors were able to successfully bridge the stent in majority of cases (5/7) with the aid of fully covered SEMS (3/5), LAMS (1/5), or NOTES $(1 / 5){ }^{11}$ Out of the patients who had technical failure (7/79), 8.9\% were managed with SEMS (4/7), over the scope clip (1/7), and surgical gastro-jejunostomy (SGJ-2/7). Half the patients with SEMS (2/4) experienced migration of the stent and consequently underwent SGJ. In a retrospective comparative study by Khashab et al. the TSR for SGJ was significantly $(p<0.009)$ higher in contrast to that for EUS-guided gastro-enterostomy (EUS-GE). ${ }^{14}$ No significant predictors for technical success were found after adjustments for age, gender, etiology, prior interventions, presence or absence of altered anatomy, and use of LAMS with or without cautery for fistula creation. ${ }^{11}$

\section{Clinical success and failure}

Clinical success was defined as the ability of the patient to tolerate oral feeds/alleviation of obstructive symptoms after successful placement of LAMS. Out of 72 patients who underwent successful placement of LAMS and creation of new entero-enteric anastomosis, 97.2\% (70/72) had clinical success. Individual clinical success rate (CSR) was $100 \%$ for all studies ${ }^{13,14,16,17,19-24}$ except one. ${ }^{11}$ Two patients (2.8\%) had persistent nausea/vomiting post procedure requiring enteral feeding despite a patent stent. ${ }^{11}$

Khashab et al. reported a higher CSR for EUS-GE group (100\%) in contrast to that for the SGJ group (90\%), but this difference lacked statistical significance. ${ }^{14}$ No significant predictors of clinical success were found after adjustments for age, gender, etiology, presence or absence of altered anatomy, prior interventions, and use of LAMS with or without cautery for fistula creation. ${ }^{11}$

Combined technical and clinical success was achieved in $88.6 \%(70 / 79)$ of the study cohorts $(n=79)$.

\section{Recurrence}

For the study cohort, over the study specific follow-up period, $97.2 \%$ of patients (70/72) remained free of obstructive symptoms. Two patients $(2.8 \%)$ had recurrence at day 88 (post procedure) and at 3 months (post LAMS removal), respectively. ${ }^{14,17}$ The first patient had obstruction secondary to a food bolus and was managed with endoscopic extraction. ${ }^{14}$ The second patient had re-stenosis at the site (4 months post procedure) and was successfully managed with re-insertion of LAMS. The underlying etiology was benign ${ }^{17}$ and malignant, ${ }^{14}$ respectively, in these two cases. Compared to EUS-GE cohort (1/26), the SGJ cohort (9/63) had a much higher abso- 
Table 2. Procedure and Stent Characteristics across Each Study

\begin{tabular}{|c|c|c|c|c|c|}
\hline Study/Location & No. & Site of intervention & Procedure technique & LAMS specifics & $\begin{array}{c}\text { Duration of } \\
\text { procedure }\end{array}$ \\
\hline $\begin{array}{l}\text { Tyberg et al. } \\
(2016)^{11} \\
\text { USA and Spain }\end{array}$ & 26 & Gastro-jejunostomy & $\begin{array}{l}\text { Techniques: } \\
\text { 1. Balloon or nasobiliary } \\
\text { drain assisted: } 16 / 26 \\
\text { 2. Hybrid rendezvous: } 5 / 26 \\
\text { 3. Direct: } 3 / 26 \\
\text { 4. Natural orifice translumi- } \\
\text { nal endoscopic surgery: } \\
\text { 2/26 }\end{array}$ & $\begin{array}{l}\text { 1. Cautery tipped } \\
\text { LAMS: } 9 / 26 \\
\text { 2. Non-cautery tipped } \\
\text { LAMS: } 17 / 26 \\
\text { Diameter: } \\
\text { 1. } 10 \mathrm{~mm}: 1 / 26 \\
\text { 2. } 15 \mathrm{~mm}: 25 / 26\end{array}$ & DNA \\
\hline $\begin{array}{l}\text { Khashab et al. } \\
(2015)^{13} \\
\text { USA ( } 2 \text { center) }\end{array}$ & 10 & $\begin{array}{l}\text { 1. Gastro-jejunosto- } \\
\text { my: } 6 / 9 \\
\text { 2. Gastro-duodenos- } \\
\text { tomy: } 3 / 9\end{array}$ & $\begin{array}{l}\text { Techniques: } \\
\text { 1. Balloon assisted: } 9 / 10 \\
\text { 2. Direct: } 1 / 10\end{array}$ & $\begin{array}{l}\text { 1. Non-cautery tipped } \\
\text { LAMS: } 9 / 9 \\
\text { D: } 15 \mathrm{~mm}\end{array}$ & $\begin{array}{l}\text { Mean: } 96 \\
\text { minutes } \\
\text { (range, } \\
45-152 \text { ) }\end{array}$ \\
\hline \multirow[t]{2}{*}{$\begin{array}{l}\text { Khashab et al. } \\
(2017)^{14} \\
\text { USA and Japan } \\
\text { (4 center) }\end{array}$} & EUS-GE: 30 & $\begin{array}{l}\text { 1. Gastro-jejunosto- } \\
\text { my } \\
\text { 2. Gastro-duodenos- } \\
\text { tomy }\end{array}$ & $\begin{array}{l}\text { 1. Balloon-assisted tech- } \\
\text { nique: } 6 / 30 \\
\text { 2. EUS-guided balloon-oc- } \\
\text { cluded gastrojejunosto- } \\
\text { my bypass: } 22 / 30 \\
\text { 3. Direct: } 2 / 30\end{array}$ & $\begin{array}{l}\text { 1. Cautery tipped } \\
\text { LAMS: } 21 / 30 \\
\text { 2. Non-cautery tipped } \\
\text { LAMS: } 7 / 30 \\
\text { 3. Niti-S Spaxus stent: } \\
\text { 2/30 }\end{array}$ & DNA \\
\hline & SGJ: 63 & Gastro-jejunostomy & $\begin{array}{l}\text { Surgical open retrocolic or } \\
\text { antecolic technique }\end{array}$ & $\mathrm{N} / \mathrm{A}$ & DNA \\
\hline $\begin{array}{l}\text { Taunk et al. } \\
(2015)^{16} \\
\text { USA }\end{array}$ & 3 & Gastro-jejunostomy & Direct technique: $3 / 3$ & $\begin{array}{l}\text { Non-cautery tipped } \\
\text { LAMS } \\
\text { D: } 15 \mathrm{~mm}\end{array}$ & DNA \\
\hline $\begin{array}{l}\text { Rodrigues-Pinto } \\
\text { et al. }(2016)^{17} \\
\text { USA }\end{array}$ & 4 & $\begin{array}{l}\text { 1. Gastro-jejunosto- } \\
\text { my: } 2 / 4 \\
\text { 2. Jejuno-jejunosto- } \\
\text { my: } 1 / 4 \\
\text { 3. Duodeno-jejunos- } \\
\text { tomy: } 1 / 4\end{array}$ & Direct technique: $4 / 4$ & $\begin{array}{l}\text { 1. Cautery tipped } \\
\text { LAMS: } 2 / 4 \\
\text { 2. Non-cautery tipped } \\
\text { LAMS: } 2 / 4 \\
\text { Diameter: } \\
\text { 1. } 10 \mathrm{~mm}: 3 / 4 \\
\text { 2. } 15 \mathrm{~mm}: 1 / 4\end{array}$ & DNA \\
\hline $\begin{array}{l}\text { Perez-Miranda } \\
\text { et al. }(2014)^{19} \\
\text { Spain }\end{array}$ & 1 & $\begin{array}{l}\text { Duodeno-jejunosto- } \\
\text { my }\end{array}$ & Nasobilliary drain-assisted & $\begin{array}{l}\text { Non-cautery tipped } \\
\text { LAMS } \\
\text { D: } 15 \mathrm{~mm}\end{array}$ & DNA \\
\hline $\begin{array}{l}\text { Shah et al. } \\
(2015)^{20} \\
\text { USA }\end{array}$ & 1 & Gastro-jejunostomy & Direct technique & $\begin{array}{l}\text { Non-cautery tipped } \\
\text { LAMS } \\
\text { D: } 15 \mathrm{~mm}\end{array}$ & DNA \\
\hline $\begin{array}{l}\text { Ikeuchi et al. } \\
(2015)^{21} \\
\text { Japan }\end{array}$ & 1 & Gastro-jejunostomy & Direct technique & $\begin{array}{l}\text { Cautery tipped LAMS } \\
\text { D: } 8 \mathrm{~mm}\end{array}$ & DNA \\
\hline $\begin{array}{l}\text { Majmudar et al. } \\
(2016)^{22} \\
\text { USA }\end{array}$ & 1 & Jejuno-jejunostomy & Direct technique & $\begin{array}{l}\text { Non-cautery tipped } \\
\text { LAMS } \\
\text { D: } 15 \mathrm{~mm}\end{array}$ & DNA \\
\hline $\begin{array}{l}\text { Küllmer et al. } \\
(2017)^{23} \\
\text { USA }\end{array}$ & 1 & Jejuno-jejunostomy & Balloon-assisted technique & $\begin{array}{l}\text { Cautery tipped LAMS } \\
\text { D: } 15 \mathrm{~mm}\end{array}$ & DNA \\
\hline $\begin{array}{l}\text { Tarantino et al. } \\
(2017)^{24} \\
\text { Italy }\end{array}$ & 1 & Gastro-jejunostomy & Balloon-assisted technique & $\begin{array}{l}\text { Cautery tipped LAMS } \\
\text { D: } 15 \mathrm{~mm}\end{array}$ & DNA \\
\hline
\end{tabular}


$\bigodot_{\text {cunncal endoscopy }}$

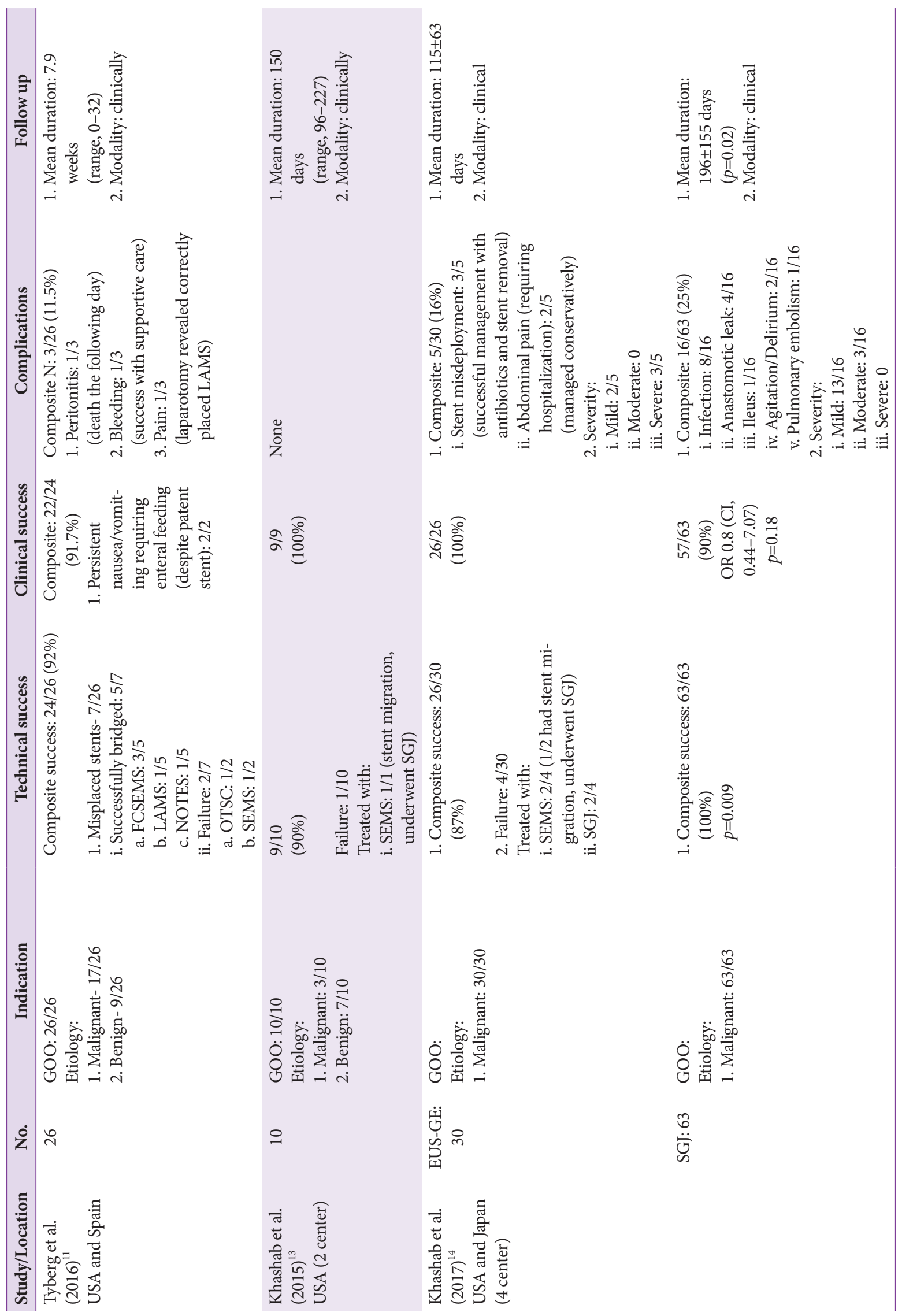




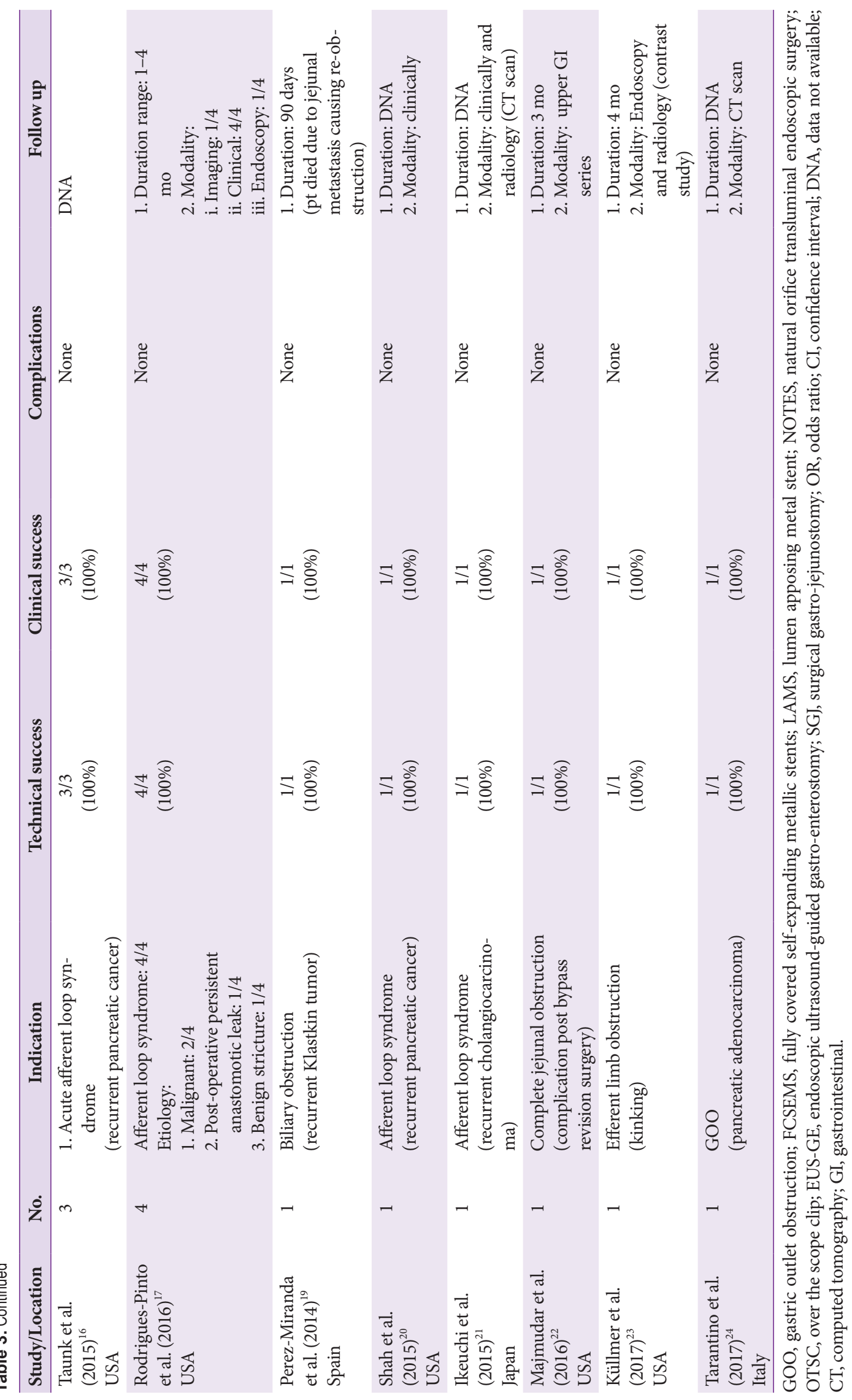


lute recurrence although statistical significance was lacking $(p=0.081)^{14}$

\section{Complications}

1. Abdominal pain: Only significant pain requiring hospitalization was considered as an adverse event. In all, 3.8\% (3/79) had significant abdominal pain. Two of them improved with supportive care alone. ${ }^{14}$ One patient underwent diagnostic laparoscopy with no obvious cause and at the discretion of surgeon, underwent SGJ. ${ }^{11}$

2. Peritonitis: Overall, 0.7\% (1/79) of patients developed this adverse event. The patient had a malignancy, ascites, and peritoneal carcinomatosis, and he died the following day. ${ }^{11}$

3. Bleeding: In total, $0.7 \%(1 / 79)$ of patients had this adverse event. This patient was successfully managed with conservative management, including blood transfusion. ${ }^{11}$

All outcomes for each individual study have been summarized in Table 3.

\section{CONCLUSIONS}

De-novo creation of gastro-enteric or entero-enteric anastomosis with the help of LAMS for patients with GOO, ALS, biliary obstruction among subjects with altered anatomy, and efferent limb obstruction, is a novel, less invasive alternative to surgery. It has been successfully used as the primary (preferred) or secondary (after prior treatment failure) treatment in management of patients with either malignant or benign etiology. The composite technical and CSR for our study cohort was $91.1 \%$ and $97.2 \%$, respectively. Only $2.8 \%$ had recurrence of symptoms and about $6.3 \%$ had some significant complications (bleeding, abdominal pain, or peritonitis). The procedure is new and various techniques have been described and used to achieve the desired outcome. It is advisable that the procedure be done only by experts at centers of excellence with adequate surgical back-up.

\section{Conflicts of Interest}

The authors have no financial conflicts of interest.

\section{Author Contributions}

Conceptualization: Deepanshu Jain

Data curation: DJ, Ankit Chhoda, Abhinav Sharma

Formal analysis: DJ

Investigation: DJ

Methodology: DJ

Project administration: DJ, Shashideep Singhal

Resources: DJ, SS

Supervision: SS
Writing-original draft: AC, AS

Writing-review\&editing: DJ, SS

\section{REFERENCES}

1. ASGE Standards of Practice Committee, Fukami N, Anderson MA, et al. The role of endoscopy in gastroduodenal obstruction and gastroparesis. Gastrointest Endosc 2011;74:13-21.

2. ASGE Standards of Practice Committee, Banerjee S, Cash BD, et al. The role of endoscopy in the management of patients with peptic ulcer disease. Gastrointest Endosc 2010;71:663-668.

3. Kozarek RA, Botoman VA, Patterson DJ. Long-term follow-up in patients who have undergone balloon dilation for gastric outlet obstruction. Gastrointest Endosc 1990;36:558-561.

4. Solt J, Bajor J, Szabó M, Horváth OP. Long-term results of balloon catheter dilation for benign gastric outlet stenosis. Endoscopy 2003;35:490495.

5. Mittal A, Windsor J, Woodfield J, Casey P, Lane M. Matched study of three methods for palliation of malignant pyloroduodenal obstruction. Br J Surg 2004;91:205-209.

6. Del Piano M, Ballarè M, Montino F, et al. Endoscopy or surgery for malignant GI outlet obstruction? Gastrointest Endosc 2005;61:421-426.

7. Khashab M, Alawad AS, Shin EJ, et al. Enteral stenting versus gastrojejunostomy for palliation of malignant gastric outlet obstruction. Surg Endosc 2013;27:2068-2075.

8. Jain D, Shah M, Patel U, Sharma A, Singhal S. Endoscopic ultrasound guided choledocho-enterostomy by using lumen apposing metal stent in patients with failed endoscopic retrograde cholangiopancreatography: a literature review. Digestion 2018;98:1-10.

9. Jain D, Bhandari BS, Agrawal N, Singhal S. Endoscopic ultrasound-guided gallbladder drainage using a lumen-apposing metal stent for acute cholecystitis: a systematic review. Clin Endosc 2018 Jun 1 [Epub]. https://doi.org.10.5946/ce.2018.024.

10. Jain D, Patel U, Ali S, Sharma A, Shah M, Singhal S. Efficacy and safety of lumen-apposing metal stent for benign gastrointestinal stricture. Ann Gastroenterol 2018;31:425-438.

11. Tyberg A, Perez-Miranda M, Sanchez-Ocaña R, et al. Endoscopic ultrasound-guided gastrojejunostomy with a lumen-apposing metal stent: a multicenter, international experience. Endosc Int Open 2016;4:E276-E281.

12. Itoi T, Ishii K, Ikeuchi N, et al. Prospective evaluation of endoscopic ultrasonography-guided double-balloon-occluded gastrojejunostomy bypass (EPASS) for malignant gastric outlet obstruction. Gut 2016;65:193195.

13. Khashab MA, Kumbhari V, Grimm IS, et al. EUS-guided gastroenterostomy: the first U.S. clinical experience (with video). Gastrointest Endosc 2015;82:932-938

14. Khashab MA, Bukhari M, Baron TH, et al. International multicenter comparative trial of endoscopic ultrasonography-guided gastroenterostomy versus surgical gastrojejunostomy for the treatment of malignant gastric outlet obstruction. Endosc Int Open 2017;5:E275-E281.

15. Chen YI, Kunda R, Storm AC, et al. EUS-guided gastroenterostomy: a multicenter study comparing the direct and balloon-assisted techniques. Gastrointest Endosc 2018;87:1215-1221.

16. Taunk P, Cosgrove N, Loren DE, Kowalski T, Siddiqui AA. Endoscopic ultrasound-guided gastroenterostomy using a lumen-apposing self-expanding metal stent for decompression of afferent loop obstruction. Endoscopy 2015;47 Suppl 1 UCTN:E395-E396.

17. Rodrigues-Pinto E, Grimm IS, Baron TH. Efficacy of endoscopically created bypass anastomosis in treatment of afferent limb syndrome: a single-center study. Clin Gastroenterol Hepatol 2016;14:633-637.

18. Ngamruengphong S, Kumbhari V, Tieu AH, et al. A novel "balloon/ 
snare apparatus" technique to facilitate easy creation of fistula tract during EUS-guided gastroenterostomy. Gastrointest Endosc 2016;84:527.

19. Perez-Miranda M, Sanchez-Ocaña R, de la Serna Higuera C, Diez-Redondo P, Nuñez H, Vallecillo MA. Transenteric anastomosis with lumen-apposing metal stent as a conduit for iterative endotherapy of malignant biliary obstruction in altered anatomy. Gastrointest Endosc 2014;80:339.

20. Shah A, Khanna L, Sethi A. Treatment of afferent limb syndrome: novel approach with endoscopic ultrasound-guided creation of a gastrojejunostomy fistula and placement of lumen-apposing stent. Endoscopy 2015;47 Suppl 1 UCTN:E309-E310.

21. Ikeuchi N, Itoi T, Tsuchiya T, Nagakawa Y, Tsuchida A. One-step EUS-guided gastrojejunostomy with use of lumen-apposing metal stent for afferent loop syndrome treatment. Gastrointest Endosc 2015;82:166.

22. Majmudar K, Wagh MS. EUS-guided jejuno-jejunostomy with lumen-apposing metal stent for complete jejunal obstruction after gastric bypass. Gastrointest Endosc 2016;84:853-854.

23. Küllmer A, Wannhoff A, Schmidt A, Caca K. Endoscopic jejunojejunostomy by use of a lumen-apposing self-expandable metal stent for treatment of obstructed efferent loop after subtotal gastrectomy with Roux-en-Y-reconstruction. Video Journal and Encyclopedia of GI Endoscopy 2017;2:276-278.

24. Tarantino I, Ligresti D, Barresi L, Curcio G, Granata A, Traina M. Onestep, exchange-free, single-balloon-assisted endoscopic ultrasound-guided gastroenterostomy with lumen-apposing metal stent in malignant gastric outlet obstruction. Endoscopy 2017;49:E92-E94. 